\title{
The patterns of toxicity and management of acute nonsteroidal anti-inflammatory drug (NSAID) overdose
}

This article was published in the following Dove Press journal:

Open Access Emergency Medicine

5 July $201 \mathrm{I}$

Number of times this article has been viewed

\section{Laura J Hunter \\ David M Wood \\ Paul I Dargan}

Clinical Toxicology, Guy's and St Thomas' NHS Foundation Trust, London, UK
Correspondence: Laura Hunter Toxicology Office, 2nd Floor, Bermondsey Wing, Guy's and St Thomas' NHS Foundation Trust, London, SEI 9RT, UK

Tel +44 207 I 885848

Fax +44 $207 \quad 188 \quad 1289$

Email laura.hunter@gstt.nhs.uk

\begin{abstract}
The nonsteroidal anti-inflammatory drugs (NSAIDs) are widely used for their analgesic, anti-inflammatory and antipyretic actions. They are commonly taken in overdose in many areas of the world. The majority of patients with acute NSAID overdose will remain asymptomatic or develop minor self-limiting gastrointestinal symptoms. However, serious clinical sequelae have been reported in patients with acute NSAID overdose and these include convulsions, metabolic acidosis, coma and acute renal failure. There appear to be some differences between the NSAIDs in terms of the relative risk of these complications; in particular mefenamic acid is most commonly associated with convulsions. The management of these serious clinical features is largely supportive and there are no specific antidotes for acute NSAID toxicity.

Keywords: nonsteroidal anti-inflammatory drugs (NSAID), ibuprofen, toxicity, poisoning, overdose, management
\end{abstract}

\section{Background}

The nonsteroidal anti-inflammatory drugs (NSAIDs) are a structurally diverse group of drugs with a common mode of action (reversible inhibition of cyclooxygenase). They are extensively used for their analgesic, antipyretic and anti-inflammatory properties; are available both as prescription and over-the-counter medications; and are available in lone pharmaceutical preparations, compound analgesic products, and in cough and cold products. This review article will discuss the epidemiology, mechanisms of toxicity, patterns of clinical presentation and management of non-salicylate NSAID poisoning. An in-depth review of the toxicity by individual NSAID preparation is beyond the scope of this paper. Therefore, the focus of the article will be on the agents most commonly used therapeutically in most areas of the world, and therefore most commonly seen in overdose: ibuprofen, naproxen, diclofenac and mefenamic acid.

\section{Epidemiology of acute NSAID poisoning}

NSAIDs are commonly ingested in overdose in many areas of the world. The 2009 Annual Report of the American Association of Poison Control Centers' National Poison Data System (NPDS) showed that analgesics were the most common category of drug in acute overdose in adult patients (10\%) and the second most common in pediatric patients $(9 \%)$. Acetaminophen alone or in combination products was the most common analgesic in acute overdose (42\%), with NSAIDs contributing to $33 \%$ of reported analgesic acute ingestions. Ibuprofen is the most common NSAID taken in overdose $(81 \%)$, followed by naproxen $(11 \%)$. This data has not changed significantly in the last decade. ${ }^{1}$ 
The situation is similar in the UK - acetaminophen is the most common agent involved in poisoning enquiries to both the National Poisons Information Service telephone service (10.2\% telephone calls) and accesses to the online TOXBASE database (6.3\% accesses). The second most common agent is the NSAID ibuprofen (4.7\% telephone enquiries and $3.7 \%$ TOXBASE accesses). ${ }^{2}$

\section{Pharmacology}

The therapeutic, and many of the toxic, effects of the NSAIDs result from reversible inhibition of the enzymes in the cyclooxygenase (COX) group. This results in a decrease in the synthesis of prostaglandins and thromboxane $\mathrm{A}_{2}$, from the precursor arachidonic acid. ${ }^{3}$

Prostaglandins have a wide variety of effects within the body. They act on the thermoregulatory center within the hypothalamus to produce fever and are involved in the regulation of inflammatory mediators and the sensitization of pain fibers. ${ }^{4}$ Therefore NSAID inhibition of these effects is responsible for the therapeutic effects of NSAIDs as antipyretic, anti-inflammatory and analgesic agents. However, prostaglandins also play an integral role in maintaining gastrointestinal mucosal integrity and renal blood flow and are also important in mediating platelet aggregation. ${ }^{4}$ These effects are responsible for many of the adverse effects seen with the therapeutic use of NSAIDs - in particular dyspepsia, gastric/duodenal ulceration and renal impairment. The gastrointestinal adverse effects of NSAIDs arise because they inhibit formation of prostaglandins that are cytoprotective within the stomach.

The majority of the NSAIDs (see Table 1) act nonspecifically on cyclooxygenase. In the early 1990s, two isoenzymes of cyclooxygenase (COX-1 and COX-2) were identified. ${ }^{5}$ COX-1 is present in most tissues throughout the body, whilst COX-2 is induced by inflammatory mediators and is therefore predominantly present at sites of inflammation. In light of this, more recently developed NSAIDs have been produced to act more specifically on the COX-2 isoenzyme with the intention of maintaining the beneficial clinical effects, whilst reducing associated gastrointestinal and renal side-effects relating to COX-1 inhibition. However, recently a number of studies have shown that therapeutic use of the COX-2 selective NSAIDs (eg, rofecoxib, celecoxib) are associated with an increased risk of cardiovascular disease and a number of these agents have been withdrawn. ${ }^{6,7}$ However, the pattern of toxicity associated with COX-2 specific overdose appears to be similar to that seen with the standard non-COX specific NSAIDs. ${ }^{8}$

\section{Pharmacokinetics}

NSAIDs are rapidly absorbed following oral ingestion, with peak concentrations occurring within 2 hours of ingestion of nonsustained release preparations. Sustained release and enteric-coated preparations generally reach peak concentrations between 2-5 hours after ingestion. ${ }^{8}$ Ingestion of supratherapeutic doses has been recognized to alter the kinetics of several NSAIDs, including naproxen and mefenamic acid, prolonging absorption and delaying attainment of peak concentrations. ${ }^{9,10}$

The NSAIDs are weakly acidic and extensively protein bound ( $>90 \%$ ), with a low volume of distribution, of approximately $0.1-0.2 \mathrm{~L} / \mathrm{kg}$. Metabolism occurs mainly by oxidation and conjugation in the liver, with renal elimination of less than $10 \%-20 \%$ of parent NSAID. ${ }^{8}$ The half-life for individual drugs varies, being approximately 2 hours for ibuprofen, diclofenac and mefenamic acid, 4 hours for indomethacin and up to 15 hours for naproxen. ${ }^{3}$

\section{Mechanisms of toxicity}

The mechanism of toxicity of NSAIDs in overdose appears to predominantly be as a result of excessive inhibition of COX-1 and subsequent reduction in prostaglandin synthesis. The metabolic acidosis seen in severe NSAID toxicity is not related to COX inhibition, but to the accumulation of acidic metabolites. ${ }^{11}$ The gastrointestinal, renal and central nervous systems (CNS) are predominantly affected, both in therapeutic use and in acute overdose.

Gastrointestinal (GI) adverse effects occur via two mechanisms. ${ }^{12}$ Prostaglandin inhibition results in reduced

Table I Non-salicylate non-steroidal anti-inflammatory drugs

\begin{tabular}{|c|c|c|c|c|}
\hline Fenamates & Acetic acids & Propionic acids & Oxicams & COX-2 specific inhibitors \\
\hline Mefenamic acid & Diclofenac & Ibuprofen & Piroxicam & Celecoxib \\
\hline \multirow[t]{5}{*}{ Meclofenamate } & Indomethacin & Flurbiprofen & & Meloxicam \\
\hline & Ketorolac & Fenoprofen & & Rofecoxib \\
\hline & & Ketoprofen & & Valecoxib \\
\hline & & Naproxen & & \\
\hline & & Oxaprocin & & \\
\hline
\end{tabular}


mucus and bicarbonate synthesis, decreased gastric blood flow and the promotion of acid production. The NSAIDs are also recognized to be directly cytotoxic to the gastric mucosa. In chronic use this results in gastrointestinal symptoms, ranging from nausea and mild epigastric discomfort to gastric/ duodenal ulceration and gastrointestinal hemorrhage. These mechanisms are also responsible for the gastrointestinal features seen in acute overdose.

The nephrotoxicity seen both with therapeutic use of NSAIDs and in NSAID overdose is related to the vasodilatory effects of prostaglandins on renal arterioles. In patients with normal physiological control of renal blood flow, NSAID nephrotoxicity is unlikely to occur at therapeutic doses, as prostaglandins' role in preservation of renal blood flow is negligible. However, in patients with low intravascular volume (eg, related to vomiting in overdose) or high levels of angiotensin (eg, patients with heart failure or cirrhosis), prostaglandin contribution to the maintenance of adequate renal blood flow is more significant. In such patients, prostaglandins are detrimental to maintaining glomerular filtration rates and inhibition may result in renal failure. Interstitial nephritis has also been reported in chronic use. ${ }^{13}$

High anion gap metabolic acidosis is recognized following large overdoses of NSAIDs and occurs due to the accumulation of acidic metabolites. ${ }^{45}$ Acidosis may also be exacerbated by vomiting and alcohol ingestion.

Inhibition of COX-1 also affects platelet aggregation, due to reduced formation of thromboxane- $\mathrm{A}_{2}$. This has implications for patients who are receiving concurrent anticoagulant or antiplatelet therapies but also produces a theoretical risk of increased bleeding in acute overdose. ${ }^{8}$ Other hematological abnormalities have been reported in individual case reports following acute overdose, but are mostly regarded as idiosyncratic; these will be discussed in the next section of the paper.

\section{Patterns of toxicity in acute NSAID overdose}

Severe poisoning and death as a result of acute poisoning with NSAIDs is extremely uncommon. The majority of cases remain asymptomatic or develop only minor gastrointestinal symptoms.

Ibuprofen is the most widely used NSAID and following its introduction as an over-the-counter (OTC) medication in the 1980s it has, as discussed earlier, become one of the most commonly overdosed drugs in many countries. ${ }^{15}$ As a result of this, ibuprofen is the NSAID with the most published data in acute overdose and a number of large series confirm that most patients with ibuprofen toxicity develop few significant clinical features. ${ }^{14-20}$ Likewise, most patients presenting with overdose of the other NSAIDs, are likely to experience only minor symptoms. ${ }^{14-20}$ However a number of reports of mefenamic acid overdose focus on the propensity of this drug to induce convulsions in acute overdose. ${ }^{10}$ In a minority of patients with very large NSAID overdose, significant clinical sequelae are reported including renal failure, acid/base disturbances and CNS toxicity. ${ }^{23-42}$ Fatalities subsequent to ingestion of NSAIDs are frequently complicated by coingestants, although fatalities in lone NSAID ingestions have been reported..$^{43}$

\section{Gastrointestinal toxicity in acute NSAID overdose}

In acute NSAID overdose reports of nausea, vomiting and epigastric discomfort are common and are usually the most prominent symptoms. ${ }^{14-20}$ Hall et al published a case series of 126 patients presenting with lone ibuprofen overdose: 19\% patients developed symptoms of mild gastrointestinal disturbances including nausea, vomiting, diarrhea and abdominal pain. ${ }^{16}$ Subsequent case reports show that minor gastrointestinal symptoms are also associated with supratherapeutic ingestions of other NSAIDs, including naproxen, ${ }^{24,25,44}$ diclofenac, ${ }^{14,26}$ indomethacin, ${ }^{17,26,45}$ and mefenamic acid. ${ }^{10,14,18}$ Significant upper gastrointestinal hemorrhage following NSAID overdose is rare. There is one reported case in a 50 -year-old female who presented after an overdose of 24-36 g of ibuprofen who developed upper GI bleeding but did not require blood transfusion. ${ }^{27}$ In another reported case, a 14-year-old developed upper gastrointestinal hemorrhage following ingestion of $50 \mathrm{~g}$ of ibuprofen. ${ }^{40}$ Perforation following NSAID overdose is also rare with only one report of duodenal perforation in a 17-year-old female who presented after an overdose of $14 \mathrm{~g}$ of ibuprofen. ${ }^{29}$

There are case reports of transient increase in liver function tests following overdose of mefenamic acid, diclofenac and naproxen. ${ }^{14,23,29-30} \mathrm{~A} 15$-year-old female was noted to have deranged liver function tests (LFTs) which normalized within 24 hours, following ingestion of 13-14 g of mefenamic acid. ${ }^{14}$ A 48-year-old male developed liver dysfunction, with a rise in aspartate aminotransferase (AST) and alkaline phosphatase and prolongation of prothrombin time (PT) and activated partial thromboplastin time (APTT), following lone ingestion of approximately $2 \mathrm{~g}$ of ibuprofen. ${ }^{30}$ No case reports of derangement of LFT's were found following acute diclofenac overdose, despite this being reported as a complication of therapeutic use. ${ }^{46}$ 


\section{Renal toxicity in acute NSAID overdose}

In acute overdose, renal impairment has been reported in patients with underlying renal and cardiovascular disease, but also in previously healthy individuals following large ingestions of ibuprofen, ${ }^{31}$ diclofenac, ${ }^{14}$ naproxen ${ }^{23}$ and mefenamic acid. ${ }^{10,31}$ Although this is partly due to the role of prostaglandins in maintaining renal blood flow, it may however be exacerbated by hypovolemia secondary to vomiting or concurrent alcohol ingestion. In a poisons center case-series of 311 cases, renal impairment was reported in two patients. ${ }^{17}$ These were a 70 -year-old man with ingestion of $>9 \mathrm{~g}$ of ibuprofen and a patient with ingestion of 12-15 $\mathrm{g}$ of mefenamic acid. In a prospective study, of 61 cases of ibuprofen overdose, there was only one report of renal failure in a 64-year-old male with ingestion of $407 \mathrm{mg} / \mathrm{kg}$ of ibuprofen. ${ }^{14}$ This patient subsequently died and is included in the table of fatalities (Table 2).

In the majority of cases, renal impairment is reversible and responsive to supportive care and intravenous fluids. . $^{14,16,17}$ However, there are reports of patients with acute NSAID toxicity requiring renal replacement therapy. . $^{14,25,32,33}$ Hemodialysis and hemofiltration may be used to manage metabolic acidosis and acute renal failure, refractory to fluid resuscitation and standard supportive care. Renal replacement therapy has no role in increasing drug elimination.

In the first of these reports, a 41-year-old male intravenous drug user ingested $36 \mathrm{~g}$ of ibuprofen over 3-4 days. He was admitted to the Emergency Department with dyspnea, hypotension, bradycardia and agitation associated with pulmonary edema. He had severe acute renal failure (potassium $7.7 \mathrm{mmol} / \mathrm{L}$, creatinine $1149 \mu \mathrm{mol} / \mathrm{L}$, urea $53.5 \mathrm{mmol} / \mathrm{L}$ ) and metabolic acidosis (pH 7.01 on arterial blood gas). Hemodialysis was commenced and was required throughout his 2-week hospital stay. His renal function failed to improve and the patient was discharged on maintenance hemodialysis which was required for 2 months. At this point his creatinine was normal. The patient was subsequently lost from follow-up. The authors identified that there were several contributing factors that made this patient high-risk to develop acute renal failure including: (i) he was an intravenous drug user; (ii) he was HIV-positive; and (iii) he had hypertension. An ultrasound scan showed enlarged kidneys with increased echogenicity, which was suggestive of underlying renal disease, but the patient refused a renal biopsy. ${ }^{33}$

There are two reports of acute renal failure in patients with diclofenac toxicity. In the first of these, a 20-year-old man developed acute renal failure (blood results not given) following ingestion of $2.5 \mathrm{~g}$ of diclofenac. This resolved within 2 days without renal replacement therapy. Coingestants in this case were not documented..$^{14}$ The second report is of a 29-year-old male who ingested $2 \mathrm{~g}$ diclofenac with alcohol. He remained asymptomatic until day 2, when he developed epigastric and lumbar pain. On day 4 his creatinine was $180 \mu \mathrm{mol} / \mathrm{L}$, with creatinine clearance of $47 \mathrm{~mL} /$ minute. His creatinine peaked on day 6 at $228 \mu \mathrm{mol} / \mathrm{L}$ but then declined to $199 \mu \mathrm{mol} / \mathrm{L}$ on day 8 when the patient self-discharged against medical advice. ${ }^{24}$

There are also two reports of nephrotoxicity in patients with naproxen toxicity. A 22-year-old male presented at day 3 after overdose of $5 \mathrm{~g}$ of naproxen with vomiting and epigastric and lumbar pain. Serum creatinine on arrival was $211 \mu \mathrm{mol} / \mathrm{L}$. Urinalysis showed proteinuria and microscopic hematuria. Serum creatinine peaked at $227 \mu \mathrm{mol} / \mathrm{L}$ on day 4 and returned to normal at 2 weeks. ${ }^{25}$ A 19 -year-old male presented 2 days after ingestion of $3.75 \mathrm{~g}$ of naproxen with malaise, vomiting and lumbar pain. Serum creatinine was $330 \mu \mathrm{mol} / \mathrm{L}$ with creatinine clearance of $25 \mathrm{~mL} /$ minute. Urinalysis showed proteinuria and microscopic hematuria. He was discharged on day 10 post ingestion with creatinine of 140 hemorrhage mol/L; 2 months later his renal function had returned to normal. ${ }^{25}$ Vomiting and hypovolemia are likely to have at least partially contributed to the development of renal toxicity in these cases.

Turnbull et al reported a 30-year-old male who presented with collapse following ingestion of approximately $12.5 \mathrm{~g}$ of mefenamic acid. ${ }^{32} \mathrm{He}$ developed convulsions and required intubation and ventilation. At presentation, serum biochemistry was normal and paracetamol and salicylate screening was negative. Twenty-four hours following admission he developed abdominal pain, vomiting and bloody diarrhea. Despite adequate hydration he developed acute renal failure with peak creatinine $(804 \mu \mathrm{mol} / \mathrm{L})$ on day 5 . This responded to conservative treatment. Renal ultrasound and intravenous urogram, performed during admission, were normal. In contrast, a case series of patients presenting following mefenamic acid overdose, published by Balali et al, did not report renal impairment in any of their 54 patients. ${ }^{10}$

\section{Neurological toxicity in acute NSAID overdose}

Drowsiness, confusion, nystagmus, blurred vision, diplopia, headache and tinnitus have been reported following overdose of ibuprofen, diclofenac and naproxen and mefenamic acid. ${ }^{10,15,16,18,29}$ These features are generally associated with larger ingestions. ${ }^{10,15}$ Auditory hallucinations have been 
reported following diclofenac overdose ${ }^{14,17}$ and dyskinesias (tongue spasms, facial grimacing, intermittent torticollis and dyskinetic limb movements) were reported in a mixed overdose of alcohol, diazepam and mefenamic acid. ${ }^{21}$

Neurological features, ranging from drowsiness to coma following ibuprofen overdose, occurred in 30\% of a cohort of 329 patients in one case series, ${ }^{19}$ while other series suggest a lower frequency of less than $10 \%{ }^{16,20}$ Significant drowsiness and reduction in the Glasgow Coma Score (GCS) in patients with NSAID poisoning is generally associated with metabolic acidosis, and significant ingestions. In ibuprofen overdose this predominantly occurs following ingestion of greater than $400 \mathrm{mg} / \mathrm{kg} .{ }^{14,24,27,30,34,40,52}$ Ingestion of other pharmaceutical agents, including alcohol, may exacerbate neurological toxicity. ${ }^{38,47}$

A 19-year-old male presented following an overdose of 200-300 ibuprofen tablets in combination with some powdered cocaine and alprazolam, 5 hours prior to attendance. Examination was unremarkable and urine screen at that time was negative for benzodiazepines and cocaine. As he was asymptomatic he was discharged to a psychiatric facility. He was subsequently returned to the Emergency Department when he became more drowsy. Arterial blood gas showed metabolic acidosis ( $\mathrm{pH}$ 7.24). Intubation was not required and he made a full recovery over the following 24 hours. ${ }^{34}$ It is possible that ingestion of alprazolam contributed to the CNS depression in this case.

Generalized convulsions occurring as a result of acute overdose of NSAIDs are predominantly associated with mefenamic acid overdose, but have also been reported following acute supratherapeutic doses of ibuprofen in children. ${ }^{16,35}$

Several case reports/series are available which demonstrate the association between mefenamic acid overdose and convulsions. In a case series of patients presenting with self-poisoning in Edinburgh over a 12-year period, 1\% (207 admissions) of all the self-poisoning admissions to their hospitals, were as a result of mefenamic acid ingestion. ${ }^{10}$ The same group subsequently published a prospective study of 54 patients presenting following acute ingestion of mefenamic acid recording both plasma concentrations and clinical features. Of 29 patients with plasma mefenamic acid levels exceeding the therapeutic range, $48 \%$ remained asymptomatic. Symptomatic patients reported vomiting (14\%) and muscle twitching (14\%) and 38\% proceeded to develop grand-mal convulsions. The mean time to convulsion following ingestion was 4.4 hours (range $2-7$ hours). Plasma concentrations were measured at admission and absorption appeared to be variable with no good correlation between mefenamic acid concentration and the occurrence of convulsions. Five patients had continued absorption following admission, with peak values occurring as late as 12 hours in some patients.

In a more recent poisons center case series, 54 cases of mefenamic acid overdose were recorded over a 2-year period. Eighty-nine percent of patients were under the age of 30 , and $83 \%$ of patients were female. Convulsions occurred in $41 \%$ of all mefenamic acid overdoses in this series, with time to onset of convulsive activity varying from 30 minutes to 12 hours post ingestion, suggesting that a longer period of observation is required in these patients. Relatively low doses of mefenamic acid were associated with convulsions: $2.5 \mathrm{~g}$ caused convulsions in a 12-year-old patient, and four patients suffered convulsions following ingestion of $5 \mathrm{~g}$ of mefenamic acid or less. ${ }^{17}$

Additionally, as discussed below, there are reports of convulsions in massive overdoses of other NSAIDs including ibuprofen and naproxen. No case reports of convulsion following overdose with diclofenac were identified in the literature.

A male patient, who had ingested $35 \mathrm{~g}$ of naproxen, was found having a convulsion. This terminated with the administration of intravenous diazepam. He recovered well with no lasting neurological sequelae. ${ }^{17}$ Metabolic acidosis and convulsions were reported in a 15-year-old female who ingested approximately $13-14 \mathrm{~g}$ of naproxen. She was responsive to pain at presentation, but developed focal convulsions which progressed to generalized convulsions. Seizure activity was not controlled with diazepam. She subsequently developed apnea, required intubation and ventilation and was commenced on a phenytoin infusion. ${ }^{14}$ Convulsions have also been reported in an adult male, following ingestion of $35 \mathrm{~g}$ Naproxen. ${ }^{17}$

Generalized convulsions have been reported following ibuprofen overdose in children. In a case series, 126 patients (38 adults, 88 children) with ibuprofen overdose, three children developed serious CNS toxicity, but there were no reports of convulsions in the adult patients. ${ }^{16}$ A 16-monthold child believed to have ingested $469 \mathrm{mg} / \mathrm{kg}$, developed apneic episodes, accompanied by generalized convulsions 4 hours following ingestion. The child developed aspiration pneumonia and subsequent sepsis; he failed to respond to supportive care and died on day $7 .{ }^{16}$ There are several subsequent case reports of apnea secondary to ibuprofen overdose in pediatric patients, associated with metabolic acidosis and CNS depression. ${ }^{35,36}$ 


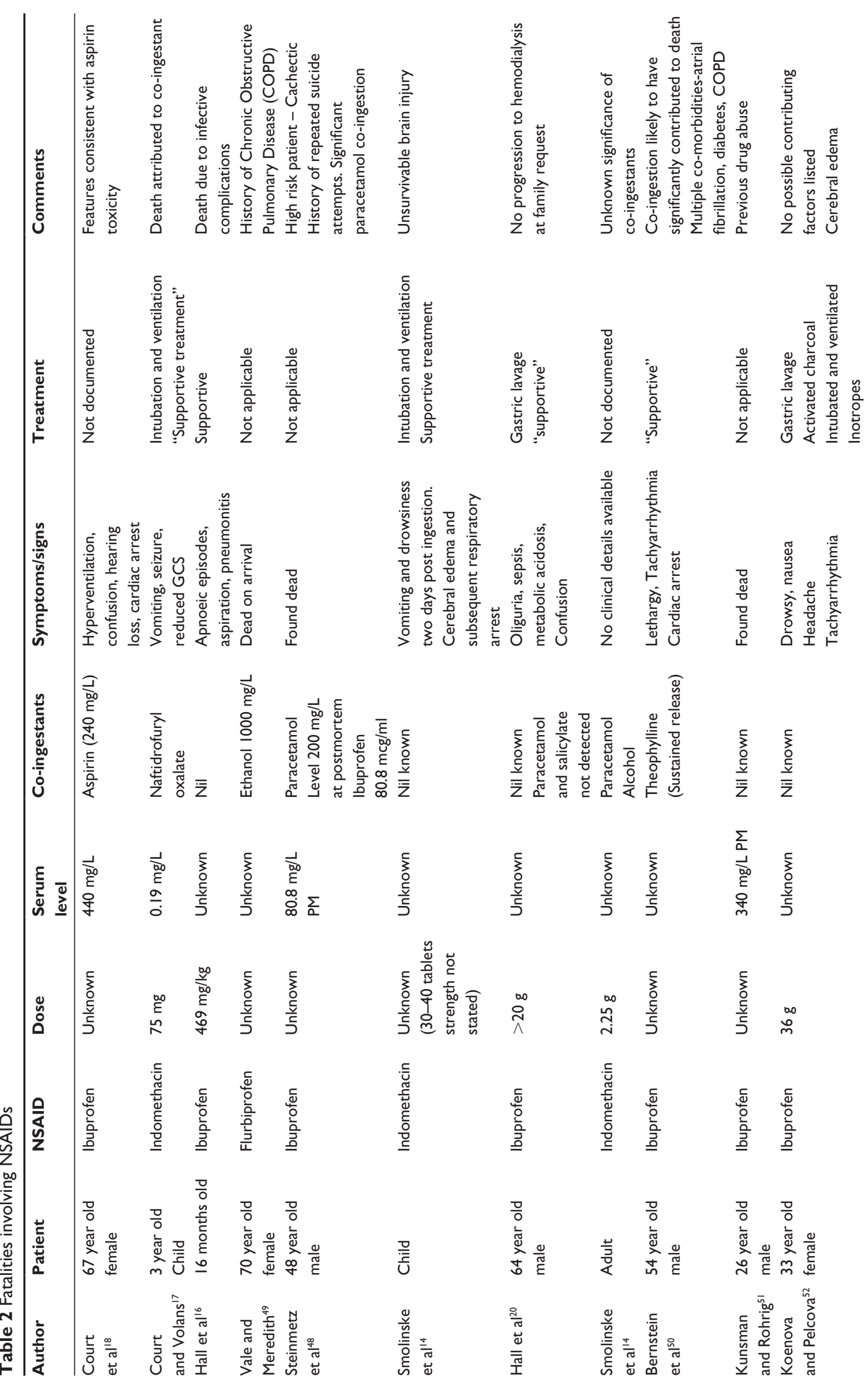



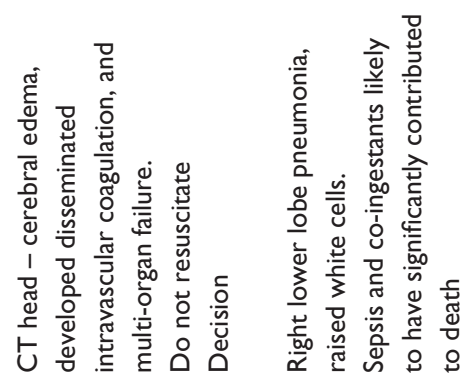

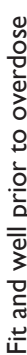
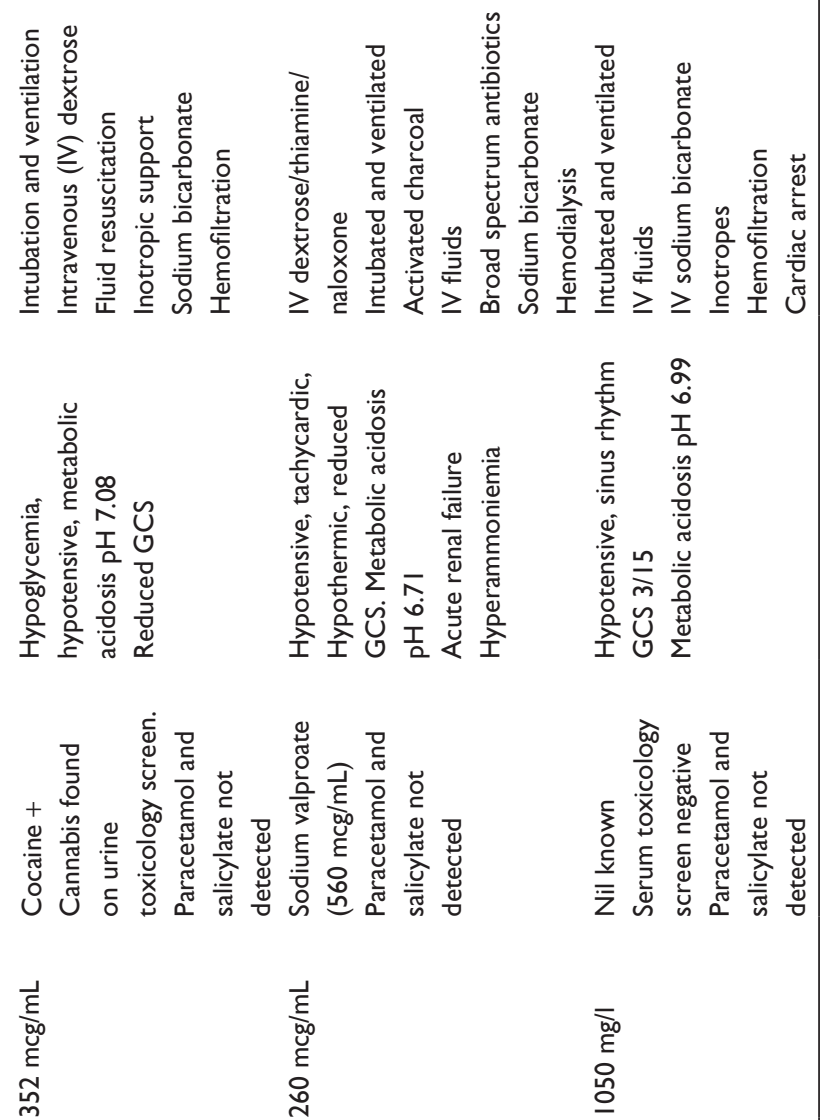

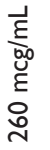

$\overline{5}$
हो
ํㅐㅇ

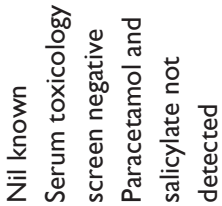

$\frac{3}{3}$
$\frac{5}{5}$
$\frac{5}{5}$

$\frac{3}{5}$
$\frac{5}{5}$

no

능

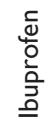

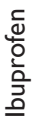

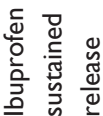

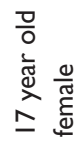

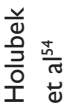

끙

¿্

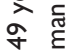

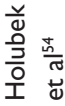

끙

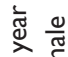

กิ

$\frac{3}{\circ} \frac{\pi}{8}$

\section{Hematological abnormalities in acute NSAID overdose}

Prolongation of prothrombin time has been reported following acute overdose of naproxen, ${ }^{44}$ indometacin, ${ }^{37}$ mefenamic acid ${ }^{17}$ and ibuprofen. ${ }^{38}$ Thrombocytopenia has also been reported in a patient who ingested $20 \mathrm{~g}$ of ibuprofen. ${ }^{30}$

\section{Biochemical abnormalities in acute NSAID overdose}

Hypokalemia, hyperkalemia and acid-base disturbances have been reported following NSAID overdose. ${ }^{53}$

Raised anion gap metabolic acidosis is recognized in acute NSAID overdose, and this occurs as a result of accumulation of acidic metabolites. ${ }^{30,31}$ Acidosis is frequently exacerbated by seizure activity, tissue hypoperfusion and hypovolemia secondary to vomiting. ${ }^{14,16,17,31,35}$ Acidosis has been reported following overdose of ibuprofen, ${ }^{11,14,16,30,31,39}$ diclofenac, ${ }^{29}$ mefenamic acid, ${ }^{21,22}$ and naproxen..$^{14,23,24}$ Acidosis is generally associated with massive overdose, and as mentioned previously is often associated with CNS toxicity, as demonstrated by the following case reports.

A 48-year-old man was admitted to hospital with leg pain and anemia of unknown origin. On the fifth day of his admission he was found unresponsive with severe metabolic acidosis (pH 7.06). Search of the patient's locker produced two empty bottles of nonprescription ibuprofen $200 \mathrm{mg}$, equivalent to a total of 100 tablets. Toxicology screens of serum and urine were positive for ibuprofen and its metabolites, but negative for paracetamol, salicylates, ethanol and toxic alcohols. ${ }^{30}$

A previously healthy 2-year-old boy attended the Emergency Department 4 hours after accidental ingestion of approximately forty, $200 \mathrm{mg}$ ibuprofen tablets $(640 \mathrm{mg} / \mathrm{kg})$. On arrival he was lethargic but irritable. He was tachycardic, but had an otherwise normal physical examination. Venous blood gas demonstrated a metabolic acidosis $(\mathrm{pH} 7.25$, $\mathrm{HCO}_{3}$ 17). He had normal renal function at presentation. Within 12 hours he had developed acute renal failure (urea $12.1 \mathrm{mmol} / \mathrm{L}$, creatinine $181 \mu \mathrm{mol} / \mathrm{L}$ ) with microscopic hematuria, in the absence of any casts or proteinuria. Urine output remained satisfactory throughout the admission $5 \mathrm{~mL} / \mathrm{kg} / \mathrm{hr}$ and renal function had returned to normal within 72 hours, with no subsequent complications. ${ }^{43}$

In 2007, a 14-year-old boy was admitted following the nonaccidental ingestion of approximately $50 \mathrm{~g}$ of ibuprofen. ${ }^{40}$ He was found to have raised anion gap metabolic acidosis, and hypotension refractory to inotropic support. He was placed on extracorporeal membrane oxygenation (ECMO) 
for cardiovascular support. He subsequently developed renal failure, pulmonary hemorrhage and gastric bleeding; it is not clear whether these complications were related to ECMO or the ibuprofen toxicity. The patient had clinically improved by day 4 and ECMO was terminated. Inotropic support was not required and he was extubated on day 5. He was medically fit for discharge 9 days after admission. There are several other reports of hypotension following large ingestions of ibuprofen, which are all associated with metabolic acidosis. ${ }^{27,41,46,54}$

\section{Fatalities in acute NSAID overdose}

There have been 14 published case reports of fatalities in patients with acute NSAID overdose, listed in Table 2; these include cases in both adults and children. As noted in the table, a significant proportion of these cases either had coingested significant quantities of other pharmaceutical agents that are likely to have contributed to death; had secondary complications (eg, infection) that contributed to death; or had significant comorbidities. However there have been five reports in which it appears that NSAID overdose was the primary cause of death: this includes four cases of ibuprofen overdose and one case of indomethacin overdose. $^{14,20,43,51,52}$

\section{Management of acute NSAID overdose}

Ingestion of small amounts of NSAIDs in children and adults are unlikely to require treatment as most patients develop self-limiting, mild gastrointestinal effects only. Serious toxicity following NSAID overdose is rare, however identification and treatment of patients with massive ingestions at risk of significant effects such as neurological toxicity, renal impairment, and metabolic acidosis is important.

Symptoms of toxicity following overdose of standard release preparations will usually occur within 4 hours of ingestion. Sustained release preparations may result in delayed onset of toxic symptoms and as noted earlier, mefenamic acid overdose can also be associated with delayedonset convulsions. Treatment in symptomatic patients is supportive, as no antidote is available.

Most data is available for ibuprofen. Several case series have demonstrated that patients who have ingested less than $100 \mathrm{mg} / \mathrm{kg}$ of ibuprofen are likely to remain asymptomatic, and that severe toxicity is generally associated with ingestions of greater than $400 \mathrm{mg} / \mathrm{kg} .{ }^{14,16,20}$ Available data on serious toxicity as a consequence of acute ingestions of other NSAIDs are less robust. Following ingestion of standard release preparations we would recommend a minimum observation time of 4 hours; this should be increased to 8 hours for those who have ingested a sustained release preparation. Acute ingestions of mefenamic acid will require 12 hours of observation because of the potential for delayed-onset convulsions. ${ }^{10}$

There are a number of OTC combination products containing ibuprofen and paracetamol (acetaminophen). It is therefore important that if there is any doubt as to what product the patient has ingested, that a plasma paracetamol concentration is checked. In patients presenting with metabolic acidosis, a plasma salicylate concentration should also be requested as there are also NSAID-salicylate combination products. There is the potential for opioid toxicity in patients who ingest an NSAID-opioid combination product - this will present with classical opioid toxicity. Paracetamol, salicylate and opioid toxicity should be managed appropriately if there is clinical or biochemical evidence of toxicity.

Laboratory quantification of plasma NSAID concentrations do not add significantly to patient management: there is a poor correlation between plasma concentrations and clinical parameters of toxicity. ${ }^{20,43}$ Patients who are symptomatic and/or those with large ingestions should have blood taken to check their full blood count, clotting, electrolytes, renal function, liver function tests and acid-base status. It is particularly important that patients with significant drowsiness and/or other neurological features should have an arterial blood gas to check for metabolic acidosis.

There are no studies which have assessed the impact of activated charcoal (or other gut decontamination methods) in the management of patients with NSAID overdose. However, the current Joint Position Statement of the American Academy of Clinical Toxicology and the European Association of Poisons Centers and Clinical Toxicologists, recommends that activated charcoal should be administered to patients who present within 1 hour of ingestion of a significant overdose, in an attempt to reduce absorption. ${ }^{55}$

Patients with significant vomiting and/or who are clinically dehydrated should have oral and/or intravenous fluid rehydration to maintain renal perfusion and good urine output. Those with established renal impairment and/or hypotension should initially be managed with fluid challenge and monitoring of fluid balance. Patients with deteriorating renal function despite supportive medical treatment may require renal replacement therapy with hemodialysis or hemofiltration, using conventional indications.

Metabolic acidosis will often respond to fluid resuscitation. However, patients with persistent metabolic acidosis despite 
fluid resuscitation may require treatment with intravenous sodium bicarbonate. We would recommend $1 \mathrm{~mL} / \mathrm{kg} 8.4 \%$ sodium bicarbonate solution in patients with a significant metabolic acidosis. It is important to ensure that patients have sufficient respiratory effort to be able to prevent a respiratory acidosis developing from carbon dioxide accumulation. Hemodialysis and hemofiltration have also been used to manage persistent acidosis and deteriorating renal function, in patients unresponsive to fluid resuscitation. These techniques do not increase total body removal of NSAIDs significantly due to the high level of protein binding.

Convulsions associated with acute NSAID overdose that are not self-terminating within 1-2 minutes should initially be managed with intravenous benzodiazepines (diazepam: $10-20 \mathrm{mg}$ in adults, $0.1-0.3 \mathrm{mg} / \mathrm{kg}$ body weight in children; lorazepam: $4 \mathrm{mg}$ in adults, $0.1 \mathrm{mg} / \mathrm{kg}$ in children). If convulsion control is not achieved, phenobarbital sodium is generally recommended as second-line therapy although there is limited data to be able to compare the use of phenobarbital with phenytoin. Paralysis, intubation and ventilation may be required for airway protection due to coma or prolonged, uncontrolled convulsion activity: in these circumstances thiopentone is the drug of choice. It is advisable to consider continuous EEG monitoring in such cases to ensure that convulsion activity is controlled as there will be no outward convulsions present.

The role of gastric protection medication in acute toxicity is not clear. Significant gastrointestinal hemorrhage secondary to acute overdose is likely to be uncommon. It is thought that upper gastrointestinal symptoms are self-limiting; however antiemetics may be required for those with persistent or severe nausea and vomiting. No studies have investigated the role of prophylactic use of antacid or acid-suppressants such as proton pump inhibitors/histamine- 2 receptor antagonists. Our current practice is to use a short (7-day course) of a proton pump inhibitor such as omeprazole or lansoprazole in patients with acute NSAID overdose who have persistent upper gastrointestinal symptoms which do not settle within a few hours of ingestion, at the stage that they are otherwise medically fit for discharge.

\section{Conclusion}

Presentation to the Emergency Department following overdose of NSAID preparations is common. Although the majority of patients will remain asymptomatic or develop only minor self-limiting symptoms, a minority of patients may develop serious clinical sequelae including renal failure, metabolic acidosis, convulsions and drowsiness progressing to coma. Prompt identification and initiation of supportive care in these individuals to allow institution of appropriate supportive therapy is important.

\section{Disclosure}

The authors report no conflicts of interest in this work.

\section{References}

1. 2009 Annual Report of the American Association of Poison Control Centers' National Poison Data System 27th Annual Report. Clinical Toxicology 2010;48(10):979-1180. Available at: http://www.aapcc. org/dnn/NPDSPoisonData/NPDSAnnualReports.aspx. Accessed April 25, 2011.

2. NPIS Annual Report 2009/2010 and Five Year Review. Available at: http:// www.hpa.org.uk/web/HPAwebFile/HPAweb_C/1284474775986. Accessed April 25, 2011.

3. Dollery C. Therapeutic Drugs. Second Edition. Edinburgh, Scotland: Churchill Livingstone; 1999.

4. Ellenhorn MJ, Schonwald S, Ordog G, Wasserberger J. Ellenhorn's Medical Toxicology: Diagnosis and Treatment of Human Poisoning. 2nd ed. Baltimore, MD: Williams and Williams; 1997.

5. Heim HK, Broich K. Selective COX-2 inhibitors and risk of thromboembolic events-regulatory aspects. J Thromb Haemost. 2006; 96(4):423-432.

6. Hillis WS. Areas of emerging interest in analgesia:cardiovascular complications. Am J Ther. 2002;9(3):259-269.

7. Baron JA, Sandler RS, Bresalier RS, et al. Cardiovascular events associated with rofecoxib: final analysis of the APPROVe trial. Lancet. 2008;372(9651):1756-1764.

8. Flomenbaum NE, Goldfrank LR, Hoffman RS, Howland MA, Lewin NA, Nelson LS. Goldfrank's Toxicologic Emergencies. 8th ed. New York: McGraw Hill; 2006.

9. Runkel R, Chaplin M, Savelius H, Ortega E, Segre E. Pharmacokinetics of naproxen overdoses. Clin Pharm Toxicol. 1976;20(3):269-277.

10. Balali-Mood M, Critchley JAJH, Proudfoot AT, Prescott LF. Mefenamic acid overdose. Lancet. 1981;1(8234):1354-1356.

11. Volans GN, Fitzpatrick R. Human Toxicity of ibuprofen. In: Rainsford KD, editor. Ibuprofen: A Critical Bibliographic Review. London, UK: Taylor and Francis: 1999; 539-559.

12. Cryer B, Kimmey MB. Gastrointestinal side effects of nonsteroidal anti-inflammatory drugs. Am J Med. 1998;105(1B):20S-30S.

13. Clive DM, Stoff J. Renal syndromes associated with nonsteroidal antiinflammatory drugs. N Engl J Med. 1984;310(9):563-572.

14. Smolinske SC, Hall AH, Vandenberg SA, Spoerke DG, McBride PV. Toxic effects of non-steroidal anti-inflammatory drugs in overdose. An overview of recent evidence on clinical effects and dose response relationships. Drug Saf. 1990;5(4):252-274.

15. Perry SJ, Streete PJ, Volans GN. Ibuprofen overdose: the first two years of over-the-counter sales. Hum Toxicol. 1987;6(2):173-178.

16. Hall A, Smolinske S, Conrad FL, et al. Ibuprofen overdose: 126 cases. Ann Emerg Med. 1986;15(11):1308-1313.

17. Court H, Volans GN. Poisoning after overdose with non-steroidal anti-inflammatory drugs. Adverse Drug React Acute Poisoning Rev. 1984;3(1):1-21.

18. Court H, Streete P, Volans GN. Acute poisoning with ibuprofen. Hum Toxicol. 1983;2(2):381-384.

19. McElwee NE, Veltri JC, Bradford DC, Rollins DE. A Prospective, population based study of acute ibuprofen overdose: complications are rare and routine and serum levels are not warranted. Ann Emerg Med. 1990;19(6):657-662.

20. Hall AH, Smolinske SC, Kulig KW, Rumack BH. Ibuprofen overdose- a prospective study. West J Med. 1988;148(6):653-656.

21. Redmond AD. Dyskinesia induced by mefanimic acid? J R Soc Med. 1981;74(7):558-559. 
22. Frank JJ, Wightkin WT, Hubner JW. Acute toxicity of nonsteroidal anti-inflammatory agents: seizure following a mefenamic acid overdose. Drug Intell Clin Pharm. 1983;17(3):204-205.

23. Martinez R, Smith DW, Frankel LR. Severe metabolic acidosis after acute naproxen sodium ingestion. Ann Emerg Med. 1989;18(10): 1102-1104.

24. Fredell EW, Strand LJ. Naproxen overdose. JAMA. 1977;238(9):938.

25. Kulling PEJ, Beckman EA, Skagius AS, Beckman EA. Renal impairment after acute diclofenac, naproxen and sulindac overdoses. JToxicol Clin Toxicol. 1995;33(2):173-177.

26. Queneau P, Barthelemy C, Fulchiron P. Ingestion massive d'indometacine en prise unique (à propos de 2 observations personelles). Lyon Med. 1978;239:133-136. French.

27. Chelluri L, Jastremski MS. Coma caused by ibuprofen overdose. Crit Care. Med 1986;14(12):1078-1079.

28. Clarke SFJ, Arepalli N, Armstrong C, Dargan PI. Duodenal perforation after ibuprofen overdose. J Toxicol Clin Toxicol. 2004;42(7): 983-985.

29. Netter P, Lambert H, Larcan A, Godbillon J, Gossert G. Diclofenac sodium-chlormezanone poisoning. Eur J Clin Pharm. 1984;26(4):535.

30. Lee CY, Finkler A. Acute intoxication due to ibuprofen overdose. Arch Pathol Lab Med. 1986;110(8):747-749.

31. Court H, Streete PJ, Volans GN. Overdose with ibuprofen causing unconsciousness and hypotension. Br Med J (Clin Res Ed). 1981;282(6269):1073.

32. Turnbull AJ, Campbell P, Hughes JA. Mefenamic acid nephropathy - acute renal failure in overdose. $\mathrm{Br}$ Med J (Clin Res Ed). 1988;296(6622):646.

33. Mattana J, Perinbasekar S, Brod-Miller C. Near fatal but reversible acute renal failure after massive ibuprofen ingestion. Am J Med Sci. 1997;313(2):117-119.

34. Lamkin S, Fraiz A. An acid/ base disturbance from ibuprofen toxicity. J Emerg Nurs. 2009;35(6):584-585.

35. Oker EE, Hermann L, Baum CR, Fentzke KM, Sigg T, Leikin JB. Serious toxicity in a young child due to ibuprofen. Acad Emerg Med. 2000;7(7):821-823.

36. Linden $\mathrm{CH}$, Townsend PL. Metabolic acidosis after acute ibuprofen overdose. J Pediatr. 1987;111(6 Pt 1):922-925.

37. Sheehan TMT, Vale JA. Indomethacin poisoning. J Toxicol Clin Toxicol. 1986;24(2):151-158.

38. O'Hanlon J, Milligan K, Wilson RL. Enhanced toxicity of cimetidine and ibuprofen overdose. Br J Intensive Care. 1993;3(10): 366-367.

39. Levine M, Khurana A, Ruha A. Polyuria, acidosis, and coma following massive ibuprofen overdose. J Med Toxicol. 2010;6(3):315-317.
40. Marciniak KE, Thomas IH, Brogan TV, Roberts TS, Czaja A, Mazor SS. Massive ibuprofen overdose requiring extracorporeal membrane oxygenation for cardiovascular support. Pediatr Crit Care Med. 2007;8(2):180-182.

41. Cole JB, Roberts DJ, Bangh SA. Massive ibuprofen ingestion resulting in coagulopathy, hypotension and coma without significant renal failure. J Toxicol Clin Toxicol. 2008;46(7):607.

42. Kim J, Gazarian M, Verjee Z, Johnson D. Acute renal insufficiency in ibuprofen overdose. Pediatr Emerg Care. 1995;11(2):107-108.

43. Wood DM, Monaghan J, Streete P, Jones AL, Dargan PI. Fatality after deliberate ingestion of sustained release ibuprofen: a case report. Crit Care. 2006;10(2):R44.

44. Waugh PK, Keatinge DW. Hypoprothrombinemia in naproxen overdose. Drug Intell Clin Pharm. 1983;17(7-8):549-550.

45. Halpern SM, Fitzpatrick R, Volans GN. Ibuprofen toxicity. A review of adverse reactions and overdose. Adv Drug React and Toxicol Reviews. 1993;12(2):107-128.

46. O'Connor N, Dargan PI, Jones AL. Hepatocellular damage from nonsteroidal anti-inflammatory drugs. QJM. 2003;96(11):787-791.

47. Hunt DP, Leigh RJ. Overdose with ibuprofen causing unconsciousness and hypotension. BMJ. 281(6253):1458-1459.

48. Steinmetz JC, Lee CY, Wu Y. Tissue levels of ibuprofen after fatal overdosage of ibuprofen and acetaminophen. Vet Hum Toxicol. 1987;29(5):381-383.

49. Vale JA, Meredith TJ. Acute Poisoning due to non-steroidal antiinflammatory drugs. Clinical Features and Management. Med Toxicol. 1986;1(1):12-31.

50. Bernstein G, Jehle D, Bernaski E, Braen GR. Failure of gastric emptying and charcoal administration in fatal sustained release theophylline overdose: pharmacobenzoar formation. Ann Emerg Med. 1992;21(11):1388-1390.

51. Kunsman GW, Rohrig TP. Tissue distribution of ibuprofen in fatal overdose. Am J Forensic Med Pathol. 1993;14(1):48-50.

52. Koenova M, Pelcova P. Fatal poisoning with ibuprofen. Clin Toxicol. 1994;43(5):537.

53. al-Harbi NN, Domrongkitchaiporn S, Lirenman DS. Hypocalcemia and hypomagnesemia after ibuprofen overdose. Ann Pharmacother. 1997;31(4):432-434.

54. Holubek W, Stolbach A, Nurok S, Lopez O, Wetter A, Nelson L. A report of two deaths from massive ibuprofen overdose. J Med Toxicol. 2007;3(2):52-55

55. Chyka PA, Seger D, Krenzelok EP, Vale JA. American Academy of Clinical Toxicology; European Association of Poisons Centres and Clinical Toxicologists. Position paper: single dose activated charcoal. J Toxicol Clin Toxicol. 2005;43(2):61-87.
Open Access Emergency Medicine

\section{Publish your work in this journal}

Open Access Emergency Medicine is an international, peer-reviewed, open access journal publishing original research, reports, editorials, reviews and commentaries on all aspects of emergency medicine. The manuscript management system is completely online and includes a very quick and fair peer-review system, which is all easy to use.

\section{Dovepress}

Visit http://www.dovepress.com/testimonials.php to read real quotes from published authors. 